\title{
UNIVERSAL DESIGN FRAMEWORK FOR THE DEVELOPMENT OF ADAPTABLE ARCHITECTURAL STUDIOS FOR LEARNING ENVIRONMENTS
}

\author{
A. Sholanke, A. Adeboye, O. Alagbe, D. Fadipe, J. lyoha \\ Department of Architecture, Covenant University (NIGERIA)
}

\begin{abstract}
Issues arising from the general problem of the inaccessibility of the built environment to people with disabilities (PWDs), have led to a paradigm shift from design approaches aimed at narrow code compliance, to design ideologies aimed at producing usable facilities and environments to meet the needs of everyone, particularly PWDs. One of such approaches is Universal Design (UD), a framework for designing products, buildings, and environments to be accessible and usable by everyone. Consequently, guidelines have been developed for many products and environments, including learning environments, in line with the UD principles. However, these models are considered inadequate to fully address design requirements of architectural studios in learning environments. This study developed a design framework for developing adaptable architectural studios, in line with UD parameters and peculiar needs of students in a traditional and digital studio learning environment. The study adopted a qualitative research approach. Observation and systematic review of relevant literature were used to collect data, which were coded according to themes for easy analysis for the development of the framework. Illustrations were employed to present the findings for clarity and easy understanding. The study outcome is a useful design guide for architects, an education material for teachers and students, and a UD repository reference material for researchers to work with and build upon as we work towards making our world more accessible and usable to all.
\end{abstract}

Keywords: Universal Design, Accessibility, Usability, Adaptability, Architecture, Studio.

\section{INTRODUCTION}

The term "universal design" was first used by Ronald L. Mace in the 1980's [1] to describe the idea of designing to meet the needs of everyone, rather than the needs of an average user who might not exist. This ideology has advanced into related ideas, such as design for all, life-span design and inclusive design [1], [2], [3] \& [4]. UD is characterized as the design of products and environments to be usable to the best degree conceivable by individuals of any age and capacities [5]. It is tied in with planning for human decent variety, social consideration and uniformity (Design for All Europe, 2008) as cited by [1]. UD is a way to deal with planning and design which goes for suiting a product or an environment to a wide variety of users [6]. It is a procedure that empowers and enables a diverse population by enhancing human performance, wellness, health and social interaction. It's an inclusive design approach towards developing accessible and usable products, systems and environments for everyone. UD has gained global prominence and now a matter of policy in countries such as Norway, UK, Canada and USA [3].

The UD concept originated from the field of architecture, but is now applied in areas such as planning, transportation, information and communication technology, education, medical and social services. It is a focus of social equity which has formed an increasing interest among young socially conscious designers [3]. The development of UD mandated that attention be paid to the usability of products and social integration amongst users. It must however be noted that the development of user-focused design extends back thousands of years and did not begin with UD. Umbach (2006) as cited by [1] noticed the notable utilization of the dimensional term "foot" as sign of our thoughtfulness regarding ergonomics. [5] opined that UD is rooted in legislative, economic social and demographic changes among older adults throughout the $20^{\text {th }}$ century. Advancement in medical sciences means that the average life expectancy has increased from 47 in the early $20^{\text {th }}$ century to 76 [6]. The global populace is thus undergoing structural alteration, involving the aging population [2], [3], [4] \& [7]. The most alarming consequence of this structural change is the increase in age associated with disabilities. $10 \%$ of people in their 50 s have serious mobility impairment, and this value exponentially increases to $50 \%$ for people in their 80 s [2]. $32 \%$ of individuals aged 55 to 64 report an inability [3]. Disability has therefore become a common condition and now far more prevalent in our urban contemporary society. 
The disability rights movement of the 1960 s and the barrier free movement of the 1950 s helped serve as catalysts for change in public practices and design policies [6]. Some significant American legislation passed as a result of these movements are: The Architectural Barriers Act of 1968 and section 504 of the Rehabilitation Act of 1973 [5]. In the European Union, Article 19 in the Fundamental Treaties of the European Union (TFEU) approved the EU to battle discrimination based on disability [3].

The evolution of UD has resulted in often confusion with accessible design [1] \& [3]. Professor Edward Steinfield explained that, while accessibility is generally concerned with development of codes, standards, policies and procedures, which is mandated legally, UD presents an innovative approach to thinking about the built environment [3]. It therefore goes beyond mere code compliance. It goes beyond usability of space, as it extends to social interaction, and the creation of a barrier free environment [8]. Soares (2007), as cited by [8] affirms that the design of spaces has always been rooted in the framework of accessibility for people with disability. However, in today's contemporary society this approach is simply inefficient. Thus, UD aims at a broader, more inclusive methodology which involves less segregation. The goal is to make accessibility issues as invisible to every user as possible [9]. The British Institute of Standards describes inclusive design as designing standard products or services to be available and usable by many individuals as reasonably conceivable, without requiring alteration or specific design [4].

UD is an important philosophical disposition which contributes to sustainable development in terms of its social equity. The world commission on environment and development (1987) explained that sustainable design is a guiding ideology to developing the built environment that addresses present requirements without compromising the capacity of future generations to address their own requirements [7]. The main idea of the concept is such that spaces of the built environment can be used by everyone [8] thus, providing inclusivity and therefore prohibiting exclusivity [7]. Imrie \& Hall (2001) as cited by [7] described the objective of UD as minimizing public tendency towards social ostracism. According to [10], the objective of UD also includes integrating the core principles of UD into designs to improve liveability and equality of live for everyone. The authors highlighted that UD can be achieved by targeting making provisions that will accommodate people of all ages, sizes and abilities. They asserted that equal merit, equal treatment and equal status are the main concepts upon which UD operates. UD therefore presents a platform for equal experience and opportunity, thus, minimizing discrimination and other forms of social injustices via the attainment of social sustainability.

According to [5], a designer is usually trained to design for a mythical average, which basically does not exist. Dr Inger Marie Lid asserted that one of the modern-day important challenges concerns is the interpretation of human plurality [3]. We have to consider everybody as having varying degrees of capability and disability rather than a twofold depiction of being abled or not [1]. UD signifies that diversity in human abilities is to be accommodated. Thus, enhancing respect for human dignity via planning which accommodates diverse groups [1].

There are seven principles of UD, which are applicable in different contexts. In summary, the principles are [11]:1. Equitable Use: The design is useful and marketable to people with diverse abilities; 2. Flexibility in Use: The design accommodates a wide range of individual preferences and abilities; 3. Simple and Intuitive: Use of the design is easy to understand, regardless of the user's experience, knowledge, language skills, or current concentration level; 4. Perceptible Information: The design communicates necessary information effectively to the user, regardless of ambient conditions or the user's sensory abilities; 5. Tolerance for Error: The design minimizes hazards and the adverse consequences of accidental or unintended actions; 6. Low Physical Effort: The design can be used efficiently and comfortably and with a minimum of fatigue; and 7. Size and Space for Approach and Use: Appropriate size and space is provided for approach, reach, manipulation, and use regardless of user's body size, posture, or mobility [6].

A review of some empirical studies on UD revealed that the issue of UD is gaining global attention and becoming relevant in different fields and areas of life. In assessing the compliance of main entrances of five purposively selected key buildings in Covenant University, Nigeria to the principles of UD, [10] asserted that the provision of easy access to the built environment is essential, towards the achievement of social sustainability. The study found that none of the selected buildings main entrances were fully UD compliant. This further reinforced the notion that some significant portions of the built environment are not fully accessible and usable to some user groups. [12] assessed UD as an evolving paradigm. The study critically analysed a transcendence in the origins and philosophy of UD, that is, from a response to an aging demographic and legislative accessibility measures, as well as the development of concepts such as inclusive design and barrier free environments. The study 
proposed strategies for effective application of UD, such as the development of UD standards, and an infusion of UD into the professional curriculum of designers. [13] identified limited access to the theoretical concept of UD. The study sought to address this shortfall by providing a critical analysis of the underlying principles of UD. It adopted a commentary method and concludes that UD is a viable path towards overcoming the disparities of access, which beleaguer the built environment, because it gives an understanding of the connection between design and disability. In a multiple case study research that appraised UD compliance of three museum buildings in Southwest Nigeria, [14] adopted a case study research approach to examine the extent to which the design, planning and construction of the selected set of museums comply with the UD principles and promote users' satisfaction. The study appraisal was based on three UD design principles of approachability, accessibility and usability. The study found that the three museums complied reasonably well in approachability but performed below average in accessibility and usability, hence their facilities and services are not very reachable and usable by all classifications of users. The study recommended the adoption of the principles of UD as a design guide for museums in the country to be accessible and usable by everyone.

As earlier applied in architecture and product design, UD for education seeks to create educational environments and products informed by a wide consideration of characteristics of people. It goes beyond accessible design, as it seeks to create a more inclusive educational experience for all involved stakeholders. These environments and products may include; classrooms, libraries, laboratories, websites, curriculum, textbooks, instructional materials and Instruction [15]. UD in education affords all students equal opportunity of learning, and experiencing the educational environment as well as targeting the best practice for teaching to meet the unique needs of each student, thereby helping students achieve the most they possibly can. According to [15], UD in education can be discussed under four main headings namely: physical spaces, instruction, information communication technology (ICT) and student services. Generally, spaces should be accessible, equipment and appliances should be easy to use, of low physical threshold, and available for use by everyone in equal measure without disparity. Circulation corridors and movement areas should be accommodative of people in different physical conditions such as: wheelchair users. All information sources must be legible, and of good contrast, as well as adaptive to users of cognitive impairment or otherwise. The environment in general must be welcoming, accessible, comfortable, easy to navigate and safe for all intended users.

Literature reveals that UD has been applied in several aspects of education, some of which include: instructional design, multimedia tutoring and learning centres, web pages, museums, conference exhibits, computer laboratories and worksites [16]. However, nothing was found on the development of an adaptable architectural studio. Architectural education like most disciplines of the arts requires a specific setting/environment that facilitates lecturing, practicing, reviewing and demonstrating [17]. The design studio is an environment for design education and interaction amongst learners and their supervisors, and thus is the most important and crucial space in the education of an architect. It is a setting for interaction which promotes creativity and collaboration [18]. Cuff (1991) as cited by [19], described the architectural studio as a combination of home and workplace. Students of Architecture spend the bulk of their time in their studios: its typical design like other learning environments, as noted by Lyons (2001) as cited by [17], is less equipped to handle the pedagogic and socio-spatial requirements of students and their instructors.

Architectural education often imposes intense workloads on students which require long work hours (as much as 80 hours per week), thus resulting in the studio being a separated work area from a campus community and society as a whole [20]. The late nights, long hours and all-nighters spent in the studio has resulted in a studio culture described by [19] as an insane little bubble of non-reality. There is therefore a need for a radical shift in the design and arrangement of a studio beyond space to place. Walck (1996) as cited by [22] gives the following assertion: "A place is where I am situated, where I find myself physically, but also emotionally, spiritually and intellectually. A place is the space I inhabit, and all the beings that inhabit with me. Place defines me, and I define it: it acts on me, and I act on it. A place encompasses and sustains me. I live in a place" pp. 5.

In Nigeria, architectural studios in institutions of learning are also used as classrooms where students take lectures and for other key aspects of architectural education such as conducting examination and juries, model making and seminars. However, it is observed that to some extent, the studios do not meet all the teaching and learning strategies used in architectural education. The design studio should be developed as an adaptable place, as it functions as a classroom, and a workspace (manual drafting or digital design) for students to constantly work on their design projects in the absence of a faculty member or supervisor [23]. In addition, it should also be a liveable space as students spend 
longer hours in them. This form the basic concept and premise of architectural educational environment. The architectural studio should therefore consider socio-spatial implications of new pedagogy which according to [23] includes: student centred, active spatial organization, problembased approach and collaborative in nature. Noting the extreme importance of the design studio to architectural education, UD concept should therefore be considered in its design to enhance collaboration and liveability in addition to effective teaching and learning activities.

None of the previous studies found and examined on UD, addressed issues on the development of adaptable architectural studio environment. Hence, this study found impetus in this knowledge gap in UD studies and sorted to fill the vacuum by developing a UD framework for the development of adaptable architectural studios, that will suit the peculiar requirements and rigors of architectural education.

\section{METHODOLOGY}

The study adopted a qualitative research approach. It relied majorly on a systematic review of relevant literature, such as UD principles, accessibility and usability guidelines, and the architecture studio as a learning location to collect data. The data were gathered between November $10^{\text {th }}, 2016$ and April $30^{\text {th }}$, 2017. The study also relied on personal experiences of the authors gathered over the years through participation and observation of architectural studio activities in various universities, polytechnics and technical institutions in Nigeria, as a data resource. Data collected were grouped according to themes for easy analysis. Descriptive approach with the use of a table and illustrations were employed to present the findings for easy understanding and clarity.

\section{RESULTS}

The seven principles of UD [6] formed by the Centre for Universal Design (CUD), in North Carolina State University in the United States, where found to be highly relevant to this study, hence was adopted with minor modifications to form an integral part of the framework proposed by this study as shown in Table 1.

Table 1. Universal Design Framework for the Development of Adaptable Architectural Studios in a Learning Environment

\begin{tabular}{|c|c|c|c|}
\hline $\mathbf{S} / \mathbf{N}$ & PRINCIPLE & DEFINITION & $\begin{array}{c}\text { HOW TO ACHIEVE UNIVERSAL } \\
\text { DESIGN }\end{array}$ \\
\hline 1 & Equitable Use & $\begin{array}{l}\text { The studio should be accessible and } \\
\text { usable for users, notwithstanding their } \\
\text { abilities }\end{array}$ & $\begin{array}{l}\text { The studio space and its facilities should } \\
\text { be designed to be within reach of use to } \\
\text { everyone, irrespective of their physical } \\
\text { conditions }\end{array}$ \\
\hline 2 & Flexible Use & $\begin{array}{l}\text { The studio should suit an extensive } \\
\text { variety of individual preferences and } \\
\text { abilities. }\end{array}$ & $\begin{array}{l}\text { The studio environment should be } \\
\text { accommodative and welcoming to users } \\
\text { with diverse range of abilities }\end{array}$ \\
\hline 3 & Simple and Intuitive & $\begin{array}{l}\text { The studio should be easily } \\
\text { understood for learners and educators } \\
\text { to use, irrespective of their } \\
\text { knowledge, experience, language } \\
\text { skills, or current level of concentration }\end{array}$ & $\begin{array}{l}\text { The studio environment, features and } \\
\text { employed assistive technologies should } \\
\text { be designed such that they are simple } \\
\text { enough for all users to use or operate }\end{array}$ \\
\hline 4 & $\begin{array}{l}\text { Perceptible } \\
\text { Information }\end{array}$ & $\begin{array}{l}\text { The studio should effectively } \\
\text { communicate needed information to } \\
\text { users, irrespective of ambient } \\
\text { conditions or their sensual abilities }\end{array}$ & $\begin{array}{l}\text { The design of studio spaces and } \\
\text { features should consider user's sensory } \\
\text { abilities to the greatest extent possible }\end{array}$ \\
\hline 5 & Tolerance for Error & $\begin{array}{l}\text { The use of the studio should limit } \\
\text { dangers and the adverse effects of } \\
\text { accidents or unintended actions }\end{array}$ & $\begin{array}{l}\text { The studio should be designed to be } \\
\text { safe to work in and reasonably danger- } \\
\text { proof }\end{array}$ \\
\hline 6 & Low Physical Effort & $\begin{array}{l}\text { The studio should be used efficiently } \\
\text { and comfortably with minimal fatigue }\end{array}$ & $\begin{array}{l}\text { The studio designed features should } \\
\text { employ low energy threshold to use }\end{array}$ \\
\hline
\end{tabular}




\begin{tabular}{|c|l|l|l|}
\hline 7 & $\begin{array}{l}\text { Size and Space for } \\
\text { Approach and Use }\end{array}$ & $\begin{array}{l}\text { Suitable space and size for approach } \\
\text { should be made available for access, } \\
\text { movements, reach, manipulation and } \\
\text { use of the studio, irrespective of } \\
\text { user's posture, body size, or mobility }\end{array}$ & $\begin{array}{l}\text { The studio layout design should take into } \\
\text { account a diverse range of users' } \\
\text { preferences, especially users who are } \\
\text { mobility impaired }\end{array}$ \\
\hline 8 & Interactive Use & $\begin{array}{l}\text { The studio should allow for interactive } \\
\text { use and be user responsive }\end{array}$ & $\begin{array}{l}\text { The studio space and its provisions } \\
\text { should be designed to allow for } \\
\text { interactive and collaborative usage }\end{array}$ \\
\hline 9 & Adaptable Use & $\begin{array}{l}\text { The studio should allow for adaptive } \\
\text { use of space, furniture, equipment, } \\
\text { fittings and fixtures }\end{array}$ & $\begin{array}{l}\text { The studio space, furniture, equipment, } \\
\text { fittings and fixtures design should allow } \\
\text { for adaptable usage for educational } \\
\text { purpose }\end{array}$ \\
\hline 10 & Livability in Use & $\begin{array}{l}\text { The studio should be comfortable to } \\
\text { work in at all times }\end{array}$ & $\begin{array}{l}\text { The studio environment and facilities } \\
\text { design should be user friendly, readily } \\
\text { accessible and usable for academic } \\
\text { purposes beyond lecture and work hours }\end{array}$ \\
\hline
\end{tabular}

The first seven principles of the framework developed by this study as shown in Table 1 were adapted from the principles of UD developed by the CUD, while the last three were developed based on the peculiarities of architectural studio culture. In addition to satisfying the seven principles of UD, this study proposes that an architectural studio environment should also be designed to allow for interactive use, adaptive use of space and movable furniture as well as accessible to use for academic purposes beyond lecture and work hours for students and their lecturers. Access points and maneuvering spaces of the studio should be wide enough to allow an average wheelchair user to pass through. Opening levers of doors, windows and cabinets together with electrical switches and sockets should be reachable and usable by all, particularly wheelchair users and other mobility impaired persons. A studio floor surface should be made of materials that are none slippery in nature when dry. Examples of how to achieve UD in line with the framework are discussed and illustrated in subsequent sections. With regards to space requirements, reach and convenience the average wheelchair user requirements were largely considered to develop the framework illustrations. It is considered that wherever an average wheelchair user can manoeuvre through to use a space or facility, able-bodied persons and other mobility impaired persons, should also be able to do same without any difficulty. Key elements of the studio discussed further with illustrations include: access ways, doors, floor finishes, windows, reach to (switches, sockets, alarms, and other appliances), circulation routes, furniture and learning mediums.

\subsection{Doors}

\subsubsection{Door Opening}

The effective opening width of access door should be at least $900 \mathrm{~mm}$ wide. If a double leaf door is used, one of the leaf should be at least $900 \mathrm{~mm}$ to allow wheelchair users to pass through.

Door Handle: Door opening handles should be reachable to all and easy to grasp with just one hand. Devices' that require a pushing action, for example, lever handles, push pads or horizontal push bars, are more easy to use than those that need concurrent lifting or twisting action. Hence, lever or bar type opening handle are preferable as they also allow varieties of opening techniques. For example, a lever type handle can be opened with an elbow for people with gripping or twisting problem, while a bar handle can be opened from any height along the bar with a pull or a push action. The use of knob handles should be avoided as twisting may prove difficult for people with arthritis or other hand or finger problems. The lowest point of the opening handle should be positioned between $800 \mathrm{~mm}$ to $1000 \mathrm{~mm}$ from the floor level as this height range is considered reachable to all user groups likely to use the studio. Where doors are provided with locks, such locks should be placed within this range. Door handles should generally contrast visually with the door for easy identification, especially for people with visual impairments. Generally, door hardware (locks and handles) should allow for easy operation by all categories of likely users. The illustrations in Fig 1 show examples of how to locate UD complaint door handles on doors. 


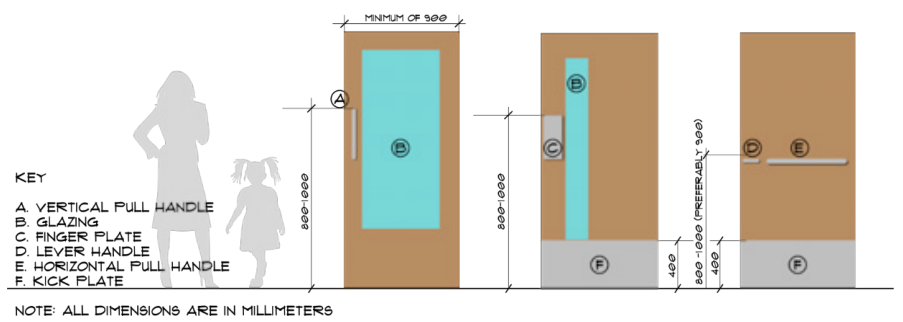

Figure 1. Door Handles

\subsubsection{Door Threshold}

Door threshold should not be too high, in order to allow easy access for wheelchair users. For this reason, the door threshold should not be more than $100 \mathrm{~mm}$ high with beveled edges.

\subsubsection{Opening Force}

Doors should be designed to open with a minimum effort. For a sliding, hinged or folding door, about five pounds of force is recommended.

\subsubsection{Automatic Doors}

Where Automatic doors are employed, ADA Standard are considered adequate. According to the ADA, an automatic door opening mechanism should be low-energy, this implies that, activating it should not require too much force. The mechanism should be capable of activing within three seconds from the moment the door is pushed or triggered, to when it comes to a halt against the back check. If there is a need to interrupt the automatic sequence, the force to achieve that should not be more than 15 pounds. It is however recommended that where automatic doors are used, a manually operated door should be provided at a reasonable distance from it as a backup in case of power failure.

\subsubsection{Number of Doors}

Architectural studios are usually large spaces that accommodate large number of students at a time. To this end, at least two doors whose effective opening width should not be less $900 \mathrm{~mm}$ should be provided at both ends of an architectural studio that accommodates between forty (40) to sixty (60) students, in order to aid easy evacuation in case of an emergency. A single door of not less than 1200 $\mathrm{mm}$ effective opening width is considered adequate for an architectural studio that does not exceed a capacity of thirty (30) students.

\subsubsection{Vision Panel}

A vision panel may be introduced for users to know of in-coming or out-going persons, thus preventing hazards associated with errors in use. The vision panels will also allow users to ascertain if a class is in use, to avoid disturbance. The positioning of the vision panel should allow users of different heights, including wheelchair users in seated position to use. Fig 2 shows two examples of vision panels located on doors.

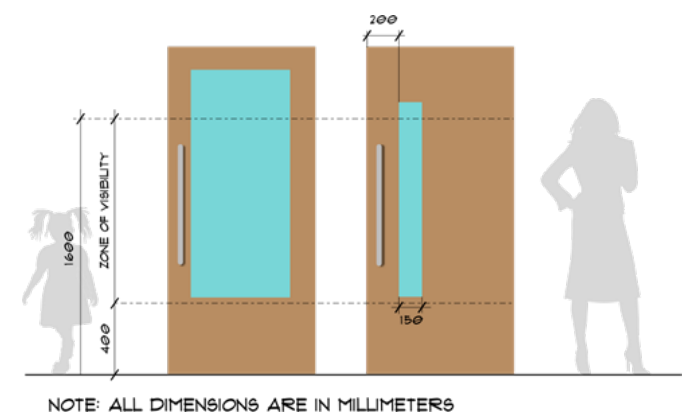

Figure 2. Vision Panels on Doors.

\subsubsection{Hinges}

The type and number of hinges should be suitable for the weight and size of a door, considering other added weights, most likely from a person leaning on the door or handle for support. 


\subsubsection{Finger Plates and Kick Plates}

Doors that need to be opened with a push action, fitted with self-closing mechanisms and opens into circulation space, should be protected against unnecessary wear with the use of kick plates and finger plates. The finger plates should be placed with the lower edge between $800 \mathrm{~mm}$ to $1000 \mathrm{~mm}$ above the floor level, and should be at least $300 \mathrm{~mm}$ high. Finger plates should visually contrast with the door for easy identification, particularly for visually impaired persons. Kick plates should be placed along the full width of the door and should be between $300 \mathrm{~mm}$ to $400 \mathrm{~mm}$ above the floor level. This will allow doors to be protected from damage by wheelchair footplates or by individuals who use their foot to hold or push the door open.

\subsection{Windows}

Opening mechanism of architectural studio windows should be simple and reachable for all users. A sliding window or louvers are easy to use in this regard as they both require low energy threshold to operate. Where windows do not open into passage ways, casement and projected windows can also be used. The lower sill height of windows should not exceed $900 \mathrm{~mm}$ height from the floor level, while opening and locking mechanisms maximum height from the floor level should not be more than 1200 $\mathrm{mm}$, so they can be accessible to wheelchair users. The distance between drawing tables from one another and between windows and the row of drawing tables closest to them are preferably between $1200 \mathrm{~mm}$ to $1500 \mathrm{~mm}$, and should not be less than $900 \mathrm{~mm}$.

\subsection{Floor surfaces}

Material to be used for the finished floor should be firm and slip resistant. The surface should resist abrasion and be suited to high traffic conditions. The slip resistant nature of the floor is to ensure user safety, particularly for those who are mobility impaired.

\subsection{Manoeuvring spaces}

Adequate manoeuvring spaces should be provided to accommodate wheelchair users. To this end, access routes within the studio should not be less than $900 \mathrm{~mm}$.

\subsection{Adaptable use of space and furniture}

Due to the peculiar nature of architectural education which involves different learning methods and environment, the studio space and its movable furniture should be adaptable for key architectural education components such as reading, writing, free hand and technical drawings, digital designs, seminar presentation, jury and model making as shown in Figs 3, 4 and 5.
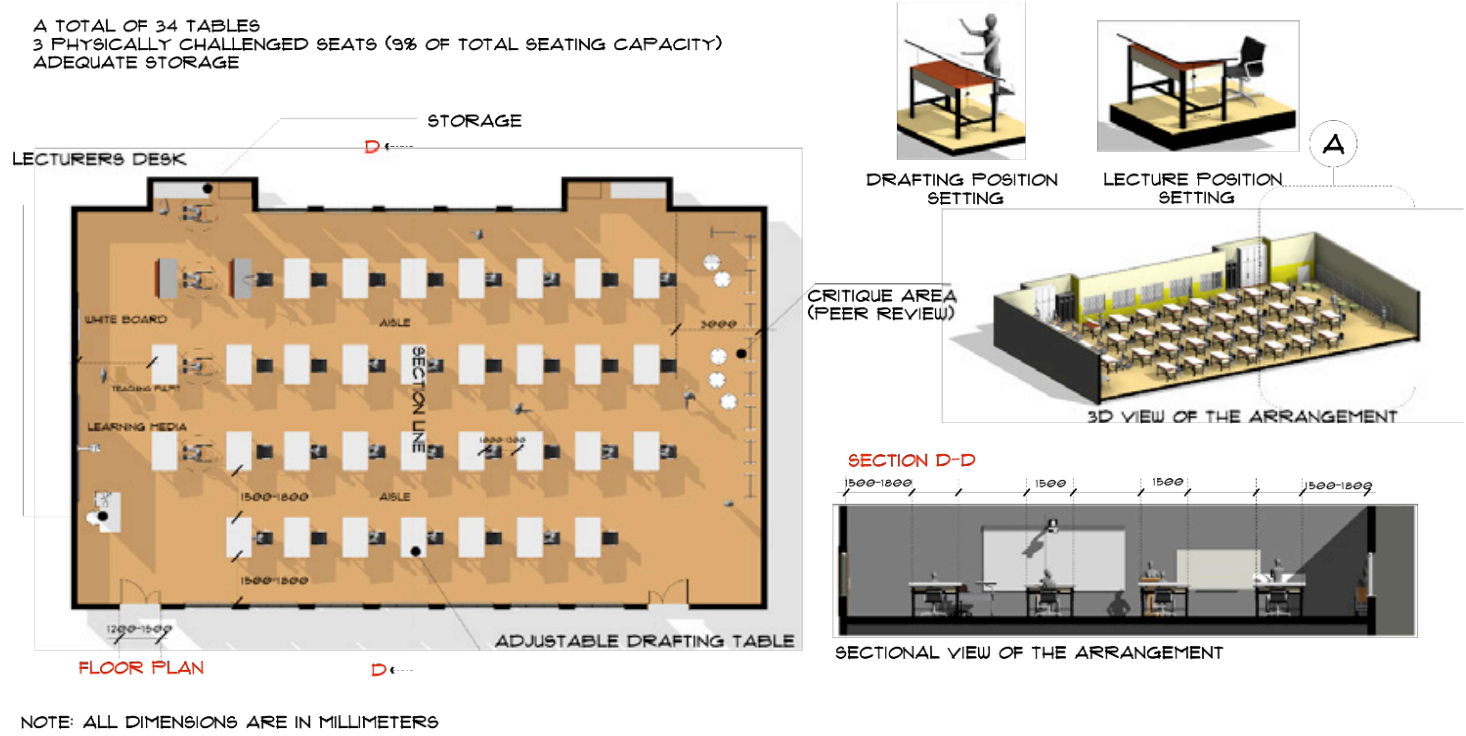

Figure 3. Example of Adapting an Architectural Studio for a Classroom, Drawing Room and Model Making Workshop Setting. 


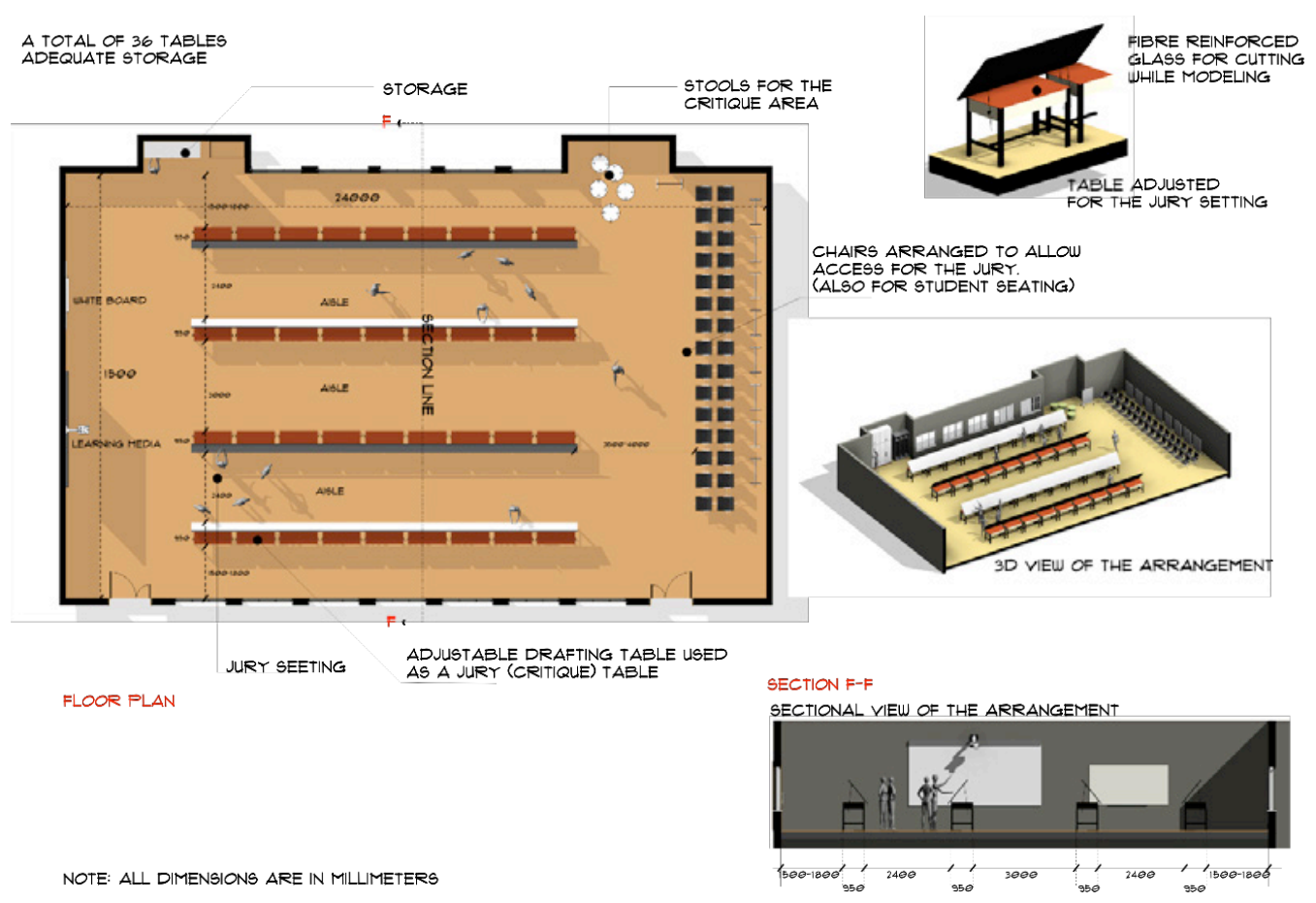

Figure 4. Example of Adapting an Architectural Studio for a Jury Setting.

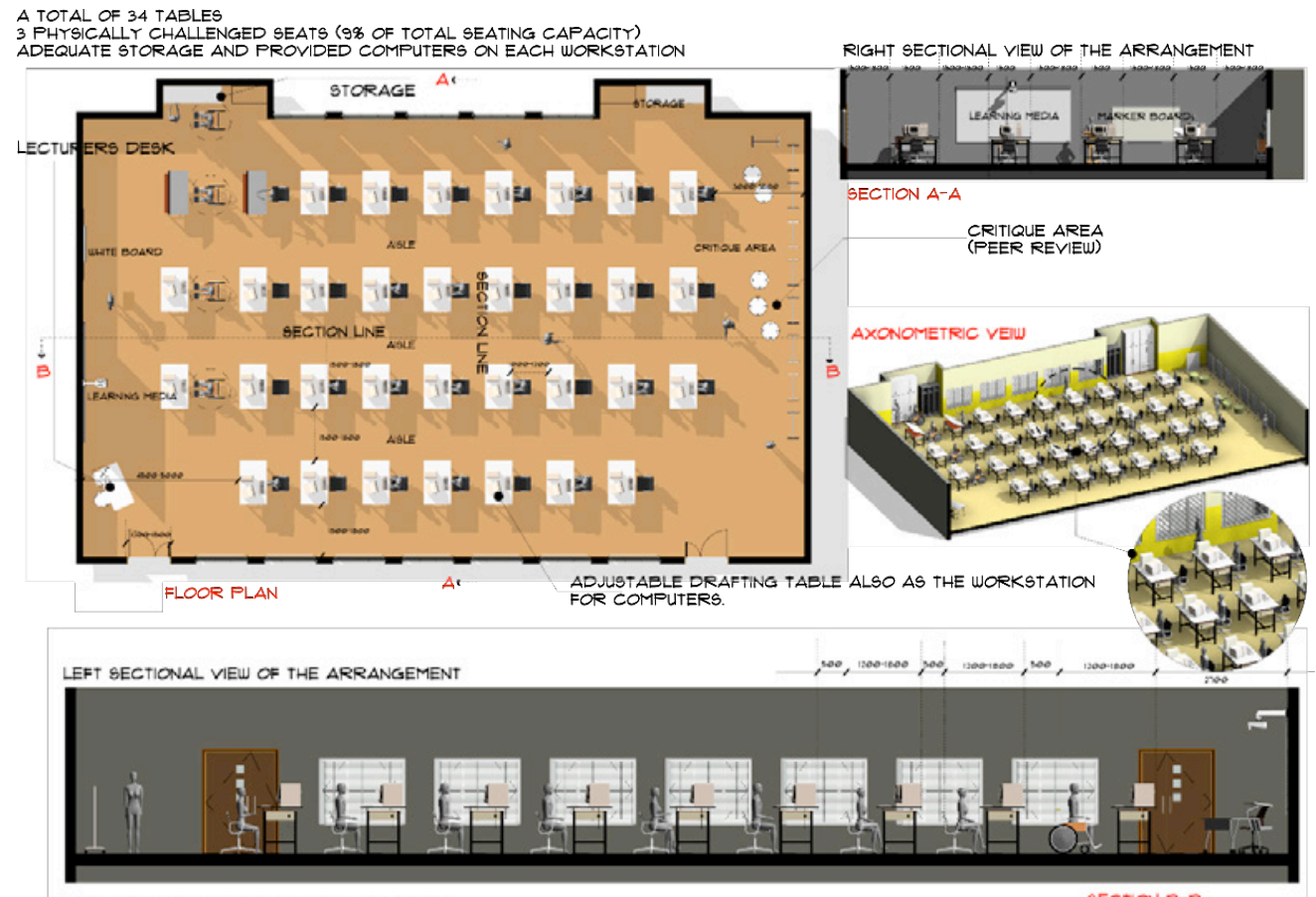

NOTE ALL DIMENSIONS ARE IN MLUMETERS

SECTION B-B

Figure 5. Example of Adapting an Architectural Studio for Digital Design Works.

Tables and chairs should be adjustable to accommodate users' preferences. In addition, tables should also be adaptable for different uses such as for reading, writing, drawing, painting, digital design works, jury, worktop and model making. This can be achieved with designs that allow the drawing boards to be detachable so that the reverse side and the table top on which the drawing board is mounted, to be used for other functions such as cutting, model making and painting. 


\subsection{Interactive use of space}

In addition to been a formal learning environment, the studio should allow for interactive and collaborative usage. To this end, seats should be handy, light weight and easily movable to allow for group discussions at any part of the studio. Reasonable free space should be allowed at the rear of a studio for display boards for exhibition and criticism of designs and projects.

\subsection{Livability in use}

The studio environment and its facilities should be user friendly, readily accessible and usable for academic purposes beyond lecture and work hours. As student spend longer hours in studios, studio seats should be soft and provided with backrest to make them comfortable to use. Adjustable leg rests could also be attached to the tables for students to rest their legs to achieve better comfort. A male and female accessible toilet with bath, a washroom and changing facilities should be attached or provided at a walking distance of not more than $50 \mathrm{~m}$ to a studio. Where more than one studio is provided, two or more studios can be grouped to make use of the same accessible toilet, bath, washroom and changing facility. The studio environment should generally be comfortable to work in at all times. To this end, the studio should be well lit and ventilated. Preferably this should be achieved naturally and can be supported with artificial means such as: electric light bulbs for lighting and fans or air conditioners for ventilation. The controls of electrical and mechanical systems employed in a studio should be reachable to all users of the studio, especially wheelchair users as shown in Fig 6 .

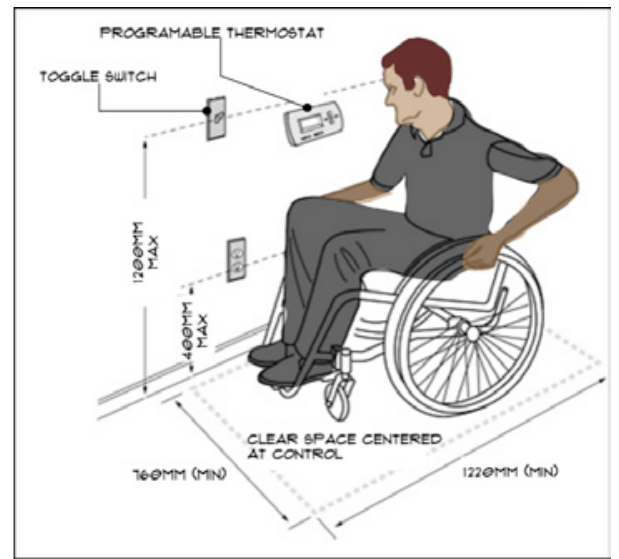

Figure 6. Dimensions to Services Control Units for Wheelchair Users

\subsection{Forward and side approaches to elements}

Clear floor space of elements should be placed for a forward or side approach. Some elements such as, switches and sockets require a forward approach for more easy access as shown in Figure 6.

\subsection{Learning mediums}

A projection screen and a marker board should be positioned at the front of a studio as learning mediums. The screen and marker board size should be such that all students in seating or standing position can easily see the whole images on them without discomfort or distortion of the images. To this end, their minimum height should be $20 \%$ of the distance to the seat farthest away from them. The width of the projection screen can be determined by the aspect ratio of projected images. 4:3 aspect ratio (screen width to screen height) is recommended. The marker board width should not be less than $2500 \mathrm{~mm}$. The use of a public-address system is recommended in a large studio that accommodates over forty (40) students, in order to aid effective hearing, especially for people with hearing impairments.

\subsubsection{Location and Orientation}

Projection screen and marker boards should be located in the direction of the seating area center of gravity, so all students seated can easily see the whole images on them. 


\subsubsection{Viewing Angles}

Unobstructed view of the entire image on the screen or board from every seat within the cones of vision (viewing angles), can be achieved as shown in Fig 7. The horizontal angle from the perpendicular to the middle of the board or screen, should not be more than 45-degrees, while the vertical angle from the perpendicular to the top part of the board or screen, should not be more than 35-degree in line with best practice.

LEARNING MEDIA

INSTALLED OFF-CENTER (SOMETIMES TWO SCREENS ARE INSTALLED) SO THAT THE CHALKBOARD CAN BE USED AT THE SAME TIME AS MATERIAL IS BEING PROJECTED.
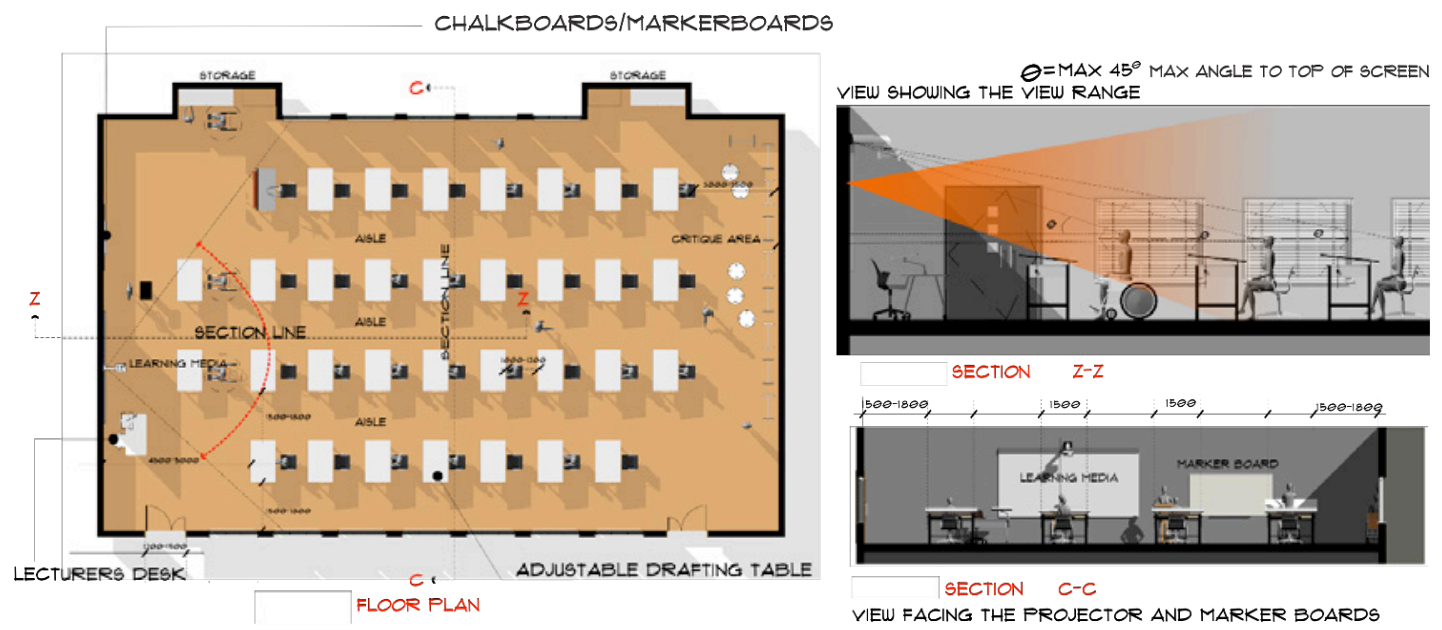

VEU FACING THE PROJECTOR AND MARKER BOARDS

NOTE: $\triangle L L$ DIMENSIONS ARE IN MILIMETERS

Figure 7. Angle of Vision.

\subsection{Furniture}

At least $5 \%$ of the tables and storage spaces in a studio should be provided and usable for wheelchair users. The tables should be provided at the front section of the studio. Adjustable tables and chairs are recommended to better accommodate students' preferences. The adjustable height range of tables should be between $700 \mathrm{~mm}$ and $900 \mathrm{~mm}$, with at least $600 \mathrm{~mm}$ knee clearance to accommodate wheelchair users. If tablet-arm chairs are provided, at least $10 \%$ of them should be accessible with the left-hand and the tablet should be provided with a textured seat. Illustrations in Fig 8 show section views of how users can reach storage spaces at different heights in a studio.

A

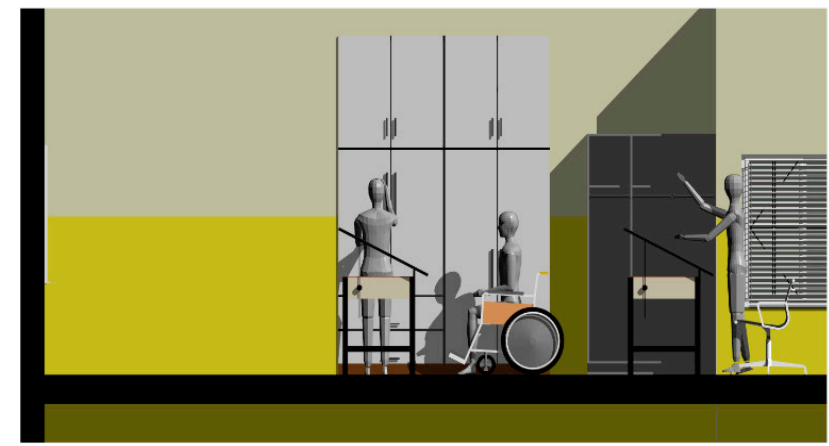

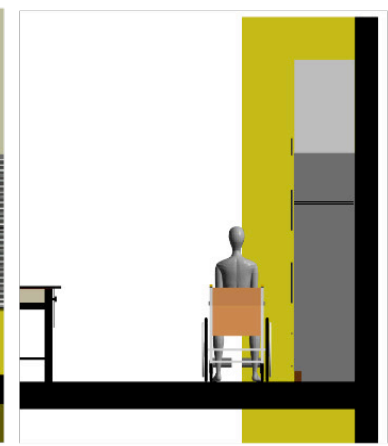

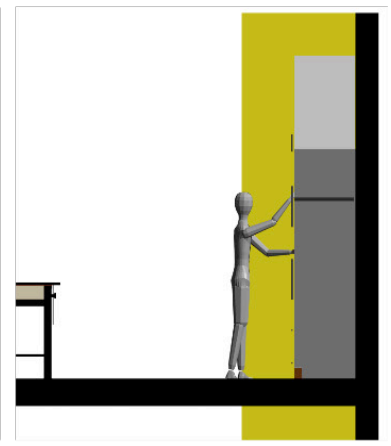

SECTIONAL VIEUS SHOWING ACCESS TO STORAGE

Diagram A: Example of how users' can reach storage spaces at different heights

Diagram B: Example of how a wheelchair user can access lower part of a storage space

Diagram C: Example of how a tall individual can reach the higher part of a storage space

Figure 8. Access to Use Storage Facilities and Tables. 


\section{CONCLUSIONS}

The UD framework for the development of adaptable architectural studios in a learning environment is envisioned to answer the enquiries of design students, educators and consultants. It is intended not to be prescriptive, but performance-oriented, so that design solutions that are creative can still be developed within the guideline, in as much as their performance objectives are met. Studio design consultants can adapt different parts of the guideline to accommodate different user group needs. Many students, educators and consultants will find the framework a useful starting point to achieving UD in the planning, designing and constructing adaptable architectural studios. Design direction has little value if it is not read, understood, and applied, Hence, all stakeholders are encouraged to study and understand this proposed design guideline for better applicability. The framework will be a useful design guide for architects, an education material for students and educators, and a UD repository reference material for researchers to work with and develop further.

\section{ACKNOWLEDGEMENTS}

The authors are grateful to Covenant University Ota, Ogun State, Nigeria, for the provision of material and financial support to carryout and publish this research work. We are also grateful to all those whose materials where used in the course of developing this paper.

\section{REFERENCES}

[1] R. Duncan, "Universal Design: Clarification and Development", A Report for the Ministry of the Environment, Government of Norway, 2007. Retrieved from http://www.universellutforming.miljo.no/file_upload/udclarification.pdf

[2] E. Helvaciouglu and N. Karamanoglu, "Awareness of the Concept of Universal Design in Design Education”, Procedia Social and Behavioural Sciences, vol. 51, pp. 99-103., 2012.

[3] The Delta Centre, Trends in Universal Design: An Anthology with Global Perspectives, Theoretical Aspects and Real-World Examples, Norway, Norwegian Directorate for Children, Youth and Family Affairs, 2013. Retrieved from https://www.bufdir.no/bibliotek/Dokumentside/?docld=BUF00002716

[4] M. Mustaquin, "Study of Universal Design in Everyday Life of Elderly Adults", Procedia Computer Science, A vol. 67, pp. 57-66, 2015.

[5] R. Mace, H. Graeme and P. Jaine, Accessible Environments: Towards Universal Design, NC State University, USA, The Centre for Universal Design, 1985. Retrieved from https://www.ncsu.edu/ncsu/design/cud/pubs_p/docs/ACC\%20Environments.pdf

[6] B. Connell, M. Jones, R. Mace, J. Mueller, A. Mullick, E. Ostroff, J. Sanford, E. Steinfeld, M. Story and G. Vanderheiden, The Principles of Universal Design, Version 2.0, NC State University, USA, The Centre for Universal Design, 1997. Retrieved from https://projects.ncsu.edu/ncsu/design/cud/about_ud/udprinciplestext.htm

[7] A. Kadir and M. Jamuladin, "Procedia- Social and Behavioural Sciences", Universal Design as a What is it and why does it matter? Significant Component for Sustainable Life and Social Development, vol. 85, pp. 179-190, 2013.

[8] C. De Souza and O. Post, "Procedia- Social and Behavioural Sciences", Universal Design: An Urgent Need, vol. 216, pp. 338-344, 2015.

[9] M. Erkilic, "Conceptual Challenges Between Universal Design and Disability in Relation to the Body, Impairment and the Environment", METU J Fac Archit, vol. 28(2), pp. 181-203, 2011.

[10] A. Sholanke, A. Adeboye, A. Oluwatayo and O. Alagbe, "Evaluation of Universal Design at the Main Entrance of Selected Public Buildings in Covenant University", Covenant University International Conference on African Development Issues (CU-ICADI), Ota, Ogun State, Nigeria, vol. 3, pp. 188-192, 2016.

[11] L. Vautier, Universal Design, Curtin University, Perth, Western Australia, 2012. 
[12] E. Ostroff, "Universal Design: An Evolving Paradigm, Universal Design Handbook, Chapter One, 1-1, 2007. Retrieved from http://citeseerx.ist.psu.edu/viewdoc/download?doi=10.1.1.642.7529\&rep=rep1\&type=pdf

[13] R. Imrie, Universal Design and Equitable Access to the Built Environment, Disability and rehabilitation, Universalism", vol. 34(10), pp. 873-882, 2012.

[14] E. Ibem, O. Oni, E. Umoren and J. Jiga, "An Appraisal of Universal Design Compliance of Museum Buildings in Southwest Nigeria", International Journal of Engineering Research, vol. 12(23), pp. 13731-13741, 2017.

[15] S. Burgstahler, "Universal Design of Instruction (UDI): Definition, Principles, Guidelines, and Examples", DO-IT, University of Washington, College of Engineering UW Technology College of Education, 2009. Retrieved from https://files.eric.ed.gov/fulltext/ED506547.pdf

[16] S. Burgstahler, "Universal Design: Principles, Process and Applications", DO-IT, University of Washington, College of Engineering UW Technology College of Education 2007. Retrieved from http://at4all.pbworks.com/f/udl+principles,+process+and+applications.pdf

[17] A. Obiedat and R. Al-share, "Quality learning Environments: Design Studio Classroom", Asian Culture and History, vol. 4(2), pp. 165-174, 2012.

[18] P. Aderonmu, O. Alagbe, P. Opoko, A. Oluwatayo and G. Alalade, "Deserted Studio and Culture in Architecture Schools: Issues of Policy and Implementation Strategies", Procedia- Social and Behavioural Sciences, vol. 00, pp. 1-5, 2013.

[19] H. Tumusiime, "Learning in Architecture: Students' Perception of the Architecture Studio", AAE Conference, 2013. Retrieved from https://architecturaleducators.files.wordpress.com/2013/12/tumusiime-2013-learning-inarchitecture-students-perceptions-of-the-architecture-studio.pdf

[20] N. Abdullah, S. Beh, M. Tahir, A. Che Ani and N. Tawil, "Architecture Design Studio Culture and Learning Spaces: A Holistic Approach to the Design and Planning of Learning Facilities", Procedia- Social and Behavioural Sciences, vol. 15, pp. 27-32, 2011.

[21] P. Monaghan, The 'Insane Little Bubble of Nonreality' that is Life for Architecture Students, Chronicle of Higher Education, vol. 47(2), pp. 34-36, 2001.

[22] P. Jamieson, "Rethinking the University Classroom: Designing Places for Learning”, 2010. Retrieved from http://www.uq.edu.au/nextgenerationlearningspace/Jamieson.pdf

[23] P. Leuth, "The Architectural Design Studio as a Learning Environment: A Qualitative Exploration of Architecture Design Student Learning Experiences in Design Studios from First-through Fourth-Year", Retrospective Thesis and Dissertation, IOWA State University Digital Repository, 2008. Retrieved from https://lib.dr.iastate.edu/cgi/viewcontent.cgi?referer=https://www.bing.com/ \&httpsredir=1\&article $=16787$ \& context=rtd 